\title{
Evaluation of the Metro C14 Stadium housing in Warsaw in Poland with FES use
}

\author{
Małgorzata Mostowska, Monika Gąsowska \\ Warsaw University of Life Sciences, Nowoursynowska 159 street, 02-776 Warsaw, Poland
}

\begin{abstract}
In Warsaw the second line of the metro has been built since 2010. The Warsaw metro will consist of 7 stations. It will be built under the Vistula river. This elaboration deals with assessing the behavior of the deep excavation on the example of the Metro C14 Stadium housing in Warsaw. This elaboration deals with assessing the behavior of the deep excavation on the example of the Metro C14 Stadium housing in Warsaw. The calculation uses the results of tests carried out by the Consortium GEOTEKO-SGGW-GEOPROJEKT in 2003-2004 and 2007, as well as sections designed in the Office Projects Metroprojekt. Calculations were performed with using the Finite Element Method with the Plaxis 9.0 programe. The results were compared with each other and their analysis has been carried out.
\end{abstract}

Keywords: diaphragm wall; finite element method; excavation.

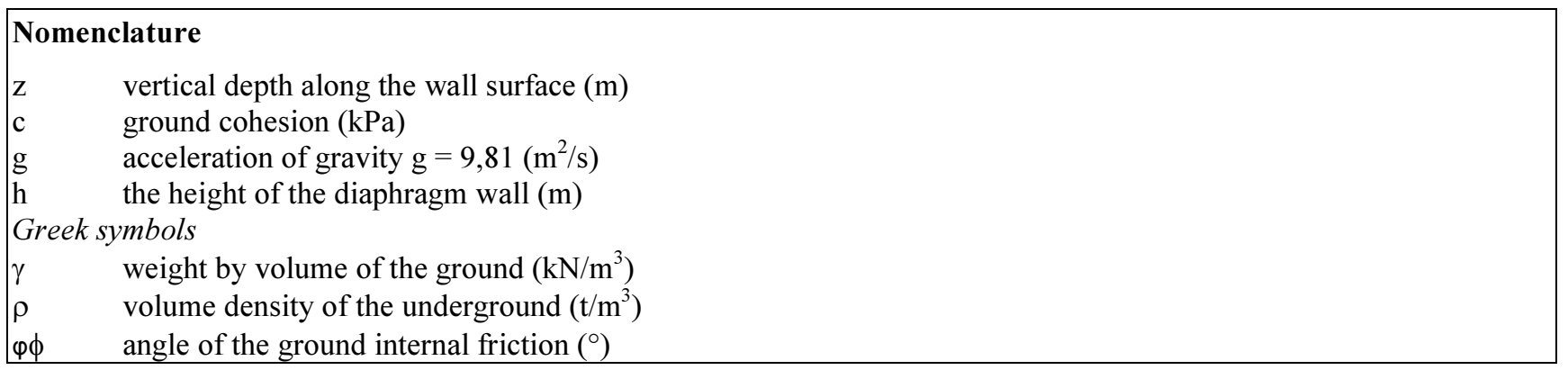

\section{Introduction}

Polish capital city-Warsaw is currently the fastest growing city in the country. Constant population growth causes the increasing of numbers of housing estates, often located in the capital city outskirts. Therefore, Warsaw as many other cities in the world, puts it's attention on a rapid development of public transport. One of the most popular, the most economical, much faster way of communication is the underground. This way of transport has been already proven in many other countries like Spain, France, Japan, Italy and Russia.

In Warsaw there is only one underground line, which connects the southern districts with the left bank of the northern part of the city. About half million passengers per day take the Warsaw underground. It can be expected, that this number will increase in the next few years. Currently the second underground line is built. The construction started in autumn 2010 . The second underway line will connect the left side of the city with the right one. The first time the underground was conducted under the Vistula River. In the right, eastern part the city line will have its two branch-lines nearby the Stadion station. The first one will end in the Bródno hausing estate, the second one in the outskirts of Gocław. The length of the whole route of the second underground line will take about $31 \mathrm{~km}$.

The central section of the second metro line will be built first, which includes the following stations: Daszyński Circle, UN Circle, Świętokrzyska St., New World St., Copernicus Science Centre, Stadium, Vilnius Railway Station. The length of the central section of the route will take approximately $6 \mathrm{~km}$.

Corresponding author: Monika Gąsowska. E-mail address: monika_gasowska@sggw.pl

http://dx.doi.org/10.3846/enviro.2014.161

(C) 2014 The Authors. Published by VGTU Press. This is an open-access article distributed under the terms of the Creative Commons Attribution License, which permits unrestricted use, distribution, and reproduction in any medium, provided the original author and source are credited. 
The construction of the second underground line is currently the largest and most capital-intensive investment in Warsaw, but first of all very complicated in relation to geotechnical conditions. The underground structures are the part of the third and the most difficult geotechnical category. Before starting this construction the range of geological, hydrogeological, geotechnical explorations, structural calculations and projects should be performed. Then you need to select the best option in respect to environmental, social and economical ways.

\section{The aim and scope of work}

This elaboration concerns the evaluation of the behavior of deep excavation housing of the station C14 Stadium the second metro line. Calculations and analysis were carried out based on data on the above-mentioned object C14 ground station, which is one of the central station. This central station is currently constructed section of the second metro line in Warsaw.

The calculations were performed using with the MES using "Plaxis 9.0". The results were compared with each other. The parameters needed for the calculation was based on research conducted by the Consortium GEOTEKO-SGGW-GEOPROJEKT in 2003-2004 and 2007. These research concerned characteristics of hydrogeological, geological and geotechnical. Cross-sections developed by Design Office Metroprojekt were also used.

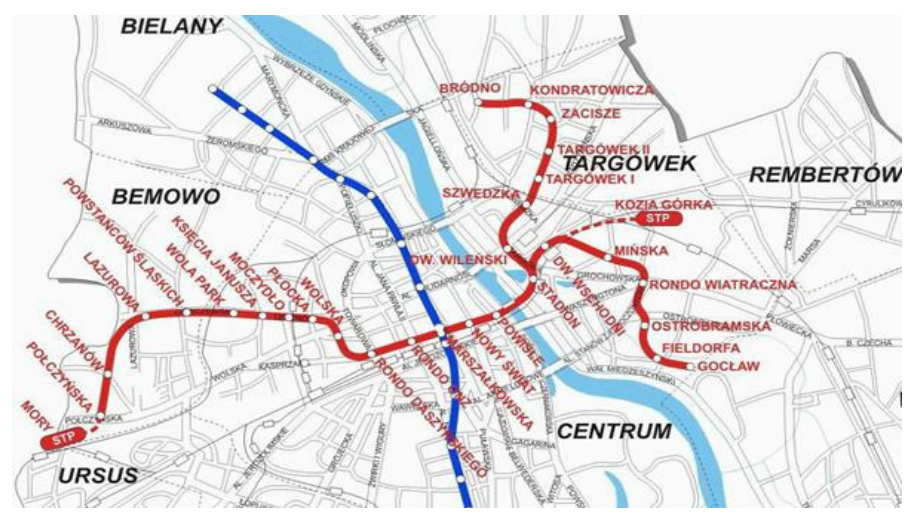

Fig. 1. Project of the II line underground

\section{General characteristics of the object}

Station C14 Stadium second metro line will be the largest underground station in Warsaw. It will be a connection between IIB line underground, which will be built in the future and bus station platforms of Stadium. It will have a complex nature of the interchange Stadion Metro Station and therefore the solution of the horizontal arrangement of the object was chosen and accepted by the Warsaw Metro.

This object will consist of the station body and holding tracks connected with the junctions for both lines with the crossovers and the passenger platforms. In the northern part of the object there will be tracks, platforms and technical part of the second metro line station. In the southern side there will be tracks, platforms and technical part for the future east-south leg of the second line of (IIB). Until the time the line IIB will start, the holding tracks and platforms of this part of the object will support the operating part of the II line station. In the lower level of the object, in it's eastern part there will be the passenger platforms of both stations, in the west part there will be the crossovers and holding tracks. In the upper level of the platform there will be localized the common mezzanine for both passenger stations, which will allow the convenient transfers between II and IIB underground line. The remaining space will occupy the upper floor separate rooms for each station technological purposes. [1]

On the both sides of the southern part of the station there were designed assembly/disassembly glass walls for the discs penetrating in the future the tunnels for east-south underground branch line IIB. Additionally, the station body was designed as a two-storey underground building. The length of the body will take $144.0 \mathrm{~m}$, the 41,6 wide distance between the walls will be devided into four bays/naves/ by raws of columns of the diameters varried from $70 \mathrm{~cm}$ in side naves to $140 \mathrm{~cm}$ ribbed ones in the centre line of the station. Column distance will take $6.0 \mathrm{~m}$. Columns in the centre line of the station will pass through the roof to grow above the ground, where they will be closed with skylights [1].

Body design will be made of reinforced concrete, monolithic housing external cavity walls $1.0 \mathrm{~m}$ thick. The walls in the implementation phase will be a cover of the excavation, and in the final phase will carry the function the external walls of the body. Depth of diaphragm walls below the base plate was from $5.0 \mathrm{~m}$ to $15.0 \mathrm{~m}$ in order to adapt to prevailing ground and 
water conditions. Widths of the platforms of both stations will take $11.0 \mathrm{~m}$. There will be ventilating ducts located below the platforms.

Mezzanine for passengers has been designed as platforms switched over the platform storey slab bands with large holes left to allow have a look at the platform level. Reinforced concrete, monolithic bottom plate $140 \mathrm{~cm}$ thick of the body will be set in the pockets of cavity walls. In the aisles crossed by tracks of II line the arched recesses in the floor have been foreseen to allow the shield travel through the body. The intermediate floor plate $60 \mathrm{~cm}$ thick above the platform hall will have the longitudinal ribs on poles. The outer walls of the slot floor slab will be based in bays and connected by combined reinforcement. External ceiling plate $100-140 \mathrm{~cm}$ thick with the holes in the center line between the beam ribs creating the center poles. The roof will be monolithically connected with diaphragm walls by curbs. In the peak body cavity walls around openings connecting with tunnels there were designed the monolithic, reinforced concrete portals combining the body structure. [1]

The platforms of both lines will be connected with the main mezzanine by stairways, escalators and elevators. Complexes of stairs will take place in open space between strands of the mezzanine floor. Exits from the station under Sokola Street will be located on top of both mezzanines just in their center line, as well as to the sidewalk by the toe of fill slope. Underway corridors will be equipped with stairways, escalators and elevators. Their construction will be monolithic, made of reinforced concrete.

Part of technological facility will be located closed to the west side of the station body and will be with it monolithically connected. The two-floor underground will have the varying length, along the second metro line it will be $131.4 \mathrm{~m}$ long, and along the track line IIB $257.4 \mathrm{~m}$. Alongside the holding tracks (temporary for the second line Metro-ultimately part of the tunnel line IIB) and in conjunction with the hollow tunnels trail line the II-nave structure with a spacing of columns on the length of $6.0 \mathrm{~m}$ has been foreseen. The height of the lower tier of the tunnel track has been determined by the gauge of the sliding shield. The upper storey over the tracks will be developed by the same technology as station II and IIB of underground lines.

\section{Characteristics of the geological, hydrogeological and geotechnical conditions}

In the above section of this object (hole OW-1) there are glacial formations of Warta river developed in the form of clay, silty clay, silty loam, silty sands and fine sands marked $\mathrm{QL}_{3}[2]$.

In the analyzed opening OW-1 it has also been identified in one of three bands described earlier, the aquifer, which form deposits dammed $\left(\mathrm{QL}_{3}\right)$ glacial Value: sand filtration medium with a coefficient in the range of $10^{-3-} 10^{-5} \mathrm{~m} / \mathrm{s}$, and the fine sands and silt sediment which are poorly permeable filtration coefficient in the range of $10^{-4-} 10^{-6} \mathrm{~m} / \mathrm{s}$ [3].

In this drilling the strained water level stabilized at a depth of $3.85 \mathrm{~m}$, while the presence of free water table was found three times at depth respectively $3.85 \mathrm{~m}, 6.80 \mathrm{~m}$ and $22.30 \mathrm{~m} \mathrm{[4].}$

In the opening OW-1 there were identified four of twenty-nine geotechnical layers described above [5].

Geotechnical layer IIIQg 3 c consists of the glacial moraine of the Warta River in form of clay sandy loamy sands on the edge of silt sands of the hard-plastic state of degree of plasticity in the range 0.0-0.2 [3].

Geotechnical VIIQl ${ }_{3} \mathrm{c}$ layer consisting of the dammed glacial formatioms of Warta River shown as silt sands, fine sands with interbeddings of silt sands in the medium and average state of density of the degree in the range of 0.6 to 0.7 . [5]

Geotechnical VIIIQr ${ }_{3}$ b layer consists of river formations of Eemian formed as the medium and coarse sands of the average degree of density from 0.4 to 0.6 [5].

Geotechnical Layer XQh-G consists of the river formations (set of common characteristics of rocks formed under different conditions) of progressive fazies as alluvial grounds taking the form of clay sands and clays with content of organic parts in plastic state with degree of plasticity 0.4 . The ground profile of the explored area the grounds are found above the roof of the proposed station and their mechanical parameters have no direct influence on working conditions of the station housing [5].

Diaphragm wall in the analyzed cross-section will be located the deepest in the comparison with the other walls of Station C14 Stadium meeting the economic and environmental requiremants [3].

At a depth of $22.3 \mathrm{~m}$ to $29.3 \mathrm{~m}$ below the surface of the land are cohesionless grounds (dusty sands) with interbeddings of cohesive sediments (silt clay). The cohesionless ground conducts water well, but water below the diaphragm wall would require drainage of the area on which the Station C14 will be built. The drainage works generate the high investment costs and is bad for the plants in the given area, as they must have continuous access to water and drainage will prevent them from water collection [4].

As you can see from the above-described characteristics of the geological, hydrogeological and geotechnical construction C14 Stadium II Station underground line is a complicated investment and required the implementation of very accurate calculations in order to secure the hill object is not threatening both people and nature. 


\section{The aim and scope of the calculations}

The aim of calculations performed with using Finite Element Method computer program Plaxis 9.0 was to check the body of C14 Stadium station consisting of diaphragm walls and bottom plate. The first step was the selection of geotechnical parameters on the basis of field and laboratory studies conducted by the Consortium GEOTEKO-SGGW-GEOPROJEKT. Then, the model was selected and according to that model the ground displacements and the values of the bending moments as well as the forces acting on the case of deep trench, based on Polish practice were calculated. The results are shown in the Tables [1].

\section{The applied model of soil and selection of parameters for the calculation}

For the calculation there was used the ground model, which was elastic-perfectly plastic on the condition of the CoulombMohr yield with an associated flow law and isotropic yield surface. Values of geotechnical parameters have been determined on the basis of field and laboratory tests carried out by the Consortium GEOTEKO-SGGW-GEOPROJEKT in 2003-2004 and 2007 [1].

Table 1. The values of geotechnical parameters for C14 Stadium Station

\begin{tabular}{|c|c|c|c|c|c|c|c|c|}
\hline Symbol & Layer name & Smbol & $\gamma\left(\mathrm{kN} / \mathrm{m}^{3)}\right.$ & $\varphi\left(^{\circ}\right)$ & $\mathrm{c}(\mathrm{kPa})$ & $\mathrm{h}(\mathrm{m})$ & $\mathrm{E}(\mathrm{MPa})$ & $v(-)$ \\
\hline XI Qh & $\begin{array}{l}\text { uncontrolled } \\
\text { embankment }\end{array}$ & $\mathrm{nN}$ & 17,5 & 30,0 & 0 & 1,2 & 20,00 & 0,35 \\
\hline \multirow[t]{2}{*}{ XQh-G } & \multirow[t]{2}{*}{ clay silt } & \multirow[t]{2}{*}{$\mathrm{G}_{\pi}$} & 21,5 & 18,0 & 32 & 0,8 & \multirow[t]{2}{*}{20,00} & \multirow[t]{2}{*}{0,35} \\
\hline & & & 21,5 & 18,0 & 32 & 1,5 & & \\
\hline $\mathrm{VIIIQr}_{3} \mathrm{~b}$ & medium sand & $\mathrm{P}_{\mathrm{s}}$ & 20,0 & 33,0 & 0 & 3,3 & 35,00 & 0,25 \\
\hline $\mathrm{VQl}_{3} \mathrm{c}$ & clay silt brief & $\mathrm{G}_{\pi \mathrm{z}}$ & 21,5 & 18,0 & 32 & 2,3 & 25,00 & 0,30 \\
\hline $\mathrm{IIIQg}_{3} \mathrm{~d}$ & sandy loam & $\mathrm{G}_{\mathrm{p}}$ & 22,0 & 23,0 & 30 & 2,0 & 30,00 & 0,30 \\
\hline \multirow[t]{2}{*}{$\mathrm{VQl}_{3} \mathrm{c}$} & clay silt brief & $\mathrm{G}_{\pi \mathrm{z}}$ & 21,5 & 18,0 & 32 & 1,6 & \multirow[t]{2}{*}{25,00} & \multirow[t]{2}{*}{0,30} \\
\hline & clay silt & $\mathrm{G}_{\pi}$ & 21,5 & 18,0 & 32 & 4,3 & & \\
\hline $\mathrm{VIIQf}_{3} \mathrm{c}$ & dusty sand & $\mathrm{P}_{\pi}$ & 19,5 & 31,5 & 0 & 4,6 & 55,00 & 0,25 \\
\hline $\mathrm{VQl}_{2} \mathrm{c}$ & clay silt & $\mathrm{G}_{\pi}$ & 21,5 & 18,0 & 32 & 0,7 & 30,00 & 0,30 \\
\hline
\end{tabular}

\section{Characteristics of computational scheme}

The calculations were made according to the scheme, which was adopted in the conceptual design of the C14 Stadium Station. The following describes the technology of the object.

The first phase will consist in forming the ground under cover - diaphragm walls and pillars temporary, which will be embedded in barettes to a depth of $1.5 \mathrm{~m}$. Barettes length is $6 \mathrm{~m}$, width $0.8 \mathrm{~m}$. Width of cavity walls will be $100 \mathrm{~m}$ and temporary posts will be varied: for pole separating from each other stations will be $0.8 \mathrm{~m}$, while for the other $-0.7 \mathrm{~m}$. Components discussed plans to do with the level of so-called reduced initial $1.0 \mathrm{~m}$ from the ground surface.

The next stage of construction of the facility will be selecting the land to the level of the underside of the roof outside. The third phase will be the concreting.

In the fourth step, select the ground to the level of the bottom of the intermediate plate and subsequently the roof brace. The sixth phase will consist in selecting the land to the level of the underside of the bottom plate and at the end of the concreting. Within the cavity walls will be constructed drainage, the water table under performed surveyed, designed to reduce the level of depression of diaphragm walls, i.e. to a depth of $30 \mathrm{~m}$. 
Table 2. Values of the maximum horizontal and vertical displacements of each of the phases after

\begin{tabular}{lcc}
\hline Workmanship phase & $\begin{array}{c}\text { Horizontal displacement } \\
(\mathrm{m})\end{array}$ & Vertical displacement $(\mathrm{m})$ \\
\hline The first phase & $2,76^{*} 10^{-3}$ & $6,14 * 10^{-3}$ \\
The second phase & $12,88^{-3} 10^{-3}$ & $27,05 * 10^{-3}$ \\
The third phase & $12,87 * 10^{-3}$ & $21,08 * 10^{-3}$ \\
The fourth phase & $10,12 * 10^{-3}$ & $57,80 * 10^{-3}$ \\
The fifth phase & $10,06 * 10^{-3}$ & $53,00 * 10^{-3}$ \\
The sixth phase & $22,30 * 10^{-3}$ & $93,39 * 10^{-3}$ \\
The seventh phase & $22,30 * 10^{-3}$ & $92,86 * 10^{-3}$ \\
\hline
\end{tabular}

Table 3. Values of maximum stress of the horizontal and vertical phase of each of the

\begin{tabular}{lcc}
\hline Phase workmanship & $\begin{array}{c}\text { Horizontal displacements } \\
(\mathrm{m})\end{array}$ & Vertical displacement (m) \\
\hline The first phase & 331,05 & 674,99 \\
The second phase & 313,92 & 636,95 \\
The third phase & $315,11^{3}$ & 656,74 \\
The fourth phase & 310,39 & 620,46 \\
The fifth phase & 311,12 & 624,23 \\
The sixth phase & 317,13 & 619,92 \\
The seventh phase & 318,38 & 619,91 \\
\hline
\end{tabular}

Table 4. The values of maximum displacement, shearing forces and bending moments for structural elements in the seventh stage

\begin{tabular}{lcccc}
\hline & Diaphragm wall & Ceiling external & Intermediate floor & Base plate \\
\hline Shipments of total $[\mathrm{m}]$ & $23,4 * 10^{-3}$ & - & - & - \\
Vertical displacement $[\mathrm{m}]$ & - & $60,43 * 10^{-3}$ & $78,62 * 10^{-3}$ & $92,86 * 10^{-3}$ \\
The shear forces $[\mathrm{kN} / \mathrm{m}]$ & 620,75 & 157,46 & 205,32 & 35,4 \\
The bending moments $[\mathrm{kN} / \mathrm{m}]$ & $1,37 * 10^{-3}$ & 360,97 & 503,58 & 183,95 \\
\hline
\end{tabular}

\section{Analysis of the results}

Comparing the maximum values of the obtained results, it was found that with each new phase the displacements as well as the stresses forcing the structure were growing, reaching the highest value after the seventh stage. However, it should be noted that at the time of removal of underground to the given depth, but before concreting the next floor the values of horizontal and vertical displacements are growing but the horizontal and vertical stresses are decreasing. After concreting the slab there is a reverse process: the displacements decreases and the tension grows.

Table 4 shows the maximum value for the total displacement of diaphragm walls, then for the outer, intermediate and bottom floor plates the values of vertical displacements, maximum shearing forces and bending moments for each of the above structural elements after the seventh phase was done. Comparing them with each other it can be seen that the total displacement of the diaphragm walls as well as the values of shearing forces and bending moments are low, which means that the walls have been designed correctly for the suitable thickness and depth. It is different in the case of ceilings and the bottom plate, where the displacement and shearing forces have small values too, but the bending moments are much higher than in the cavity walls. Probably this is due to the fact that the ceiling and bottom plate have large spans too small in relation to their thickness and are placed on great depths. 


\section{Conclusions}

The analyzed object in this elaboration is one of the stations which is the part of actually built central section of the second line of Warsaw Underground. The object C14 Stadium is planned to be placed in the casing of diaphragm walls. It will be made by joist. Station C14 is the most complicated of all the stations that exist and are to be built, and because of it's conceptual design has the character of the horizontally composed interchange object. On the basis of this analysis and calculation results the conclusions are standing as below.

- The foundation of the C14 Stadium station in shielded cavity walls and using ceilings as the spacers is cheap and does not disturb further earthworks and also provides adequate protection of the trench against losing its stability.

- Besides, the use of spacers as the spreading elements eliminates a collision between the object and the existing underground infrastructure as well as positively reduces its impact on the buildings located around. Such situation would occur in the case of using cavity walls reinforced by anchors.

- The obtained results inform us about the state of stress and deformation of the substructure in the area of the proposed station C14. Due to the increasing popularity of numerical methods, it is recommended not only rely just on calculations made using Finite Element Method.

- The obtained values of horizontal displacements and bending moments for the slab and the base plate are acceptable, but for safety reasons they should be reduced.

- In order to reduce overlap and horizontal displacements of the floor immediately after concreting the back filling to it's upper level is necessary.

- Regarding to the base plate of the value of vertical displacement was equal to $92 \mathrm{~mm}$. In order to reduce this strain it is suggested to increase the thickness of the plate, which currently takes $1.2 \mathrm{~m}$.

- At the time of deep removal of the soil you should be aware that there will be a slight relaxation of the ground, however, it is suggested to monitor these situations constantly.

- The obtained results are based on the data from the conceptual design of the second underground line in Warsaw. Therefore, it should be noticed, that the structural dimensions shown in this elaboration are subject to change.

\section{References}

[1] Mostowska, M. 2010. Evaluation of the Metro S13 Stadium housing in Warsaw using FES: Master's Thesis, SGGW (WULS), Warsaw, 120.

[2] The consortium GEOTEKO - SGGW - GEOPROJEKT. 2003-2004. Documentation of Geology Engineering and Hydrological for the second line of the Warsaw Metro - station S13 Stadium, Warsaw.

[3] Wolski, W. 2007. The geological structure, in Documentation geological engineering the revised route the second metro line in Warsaw on the section station New World - Vilnius Train Station, Warsaw.

[4] Wolski, W. 2007. The hydrogeological conditions, in Geological - Engineering for the revised route the second metro line in Warsaw on the section station New World - Vilnius Train Station, Warsaw.

[5] Wolski, W. 2007. Characteristics of engineering - geological, in Documentation geological and engineering for the revised route the second metro line in Warsaw on the section station New World - Vilnius Train Station, Warsaw. 